EESTI NSV TEADUSTE AKADEEMIA TOIMETISED. 21. KÖIDE

KEEMIA * GEOLOOGIA, 1972, NR, 2

ИЗВЕСТИЯ АКАДЕМИИ НАУК ЭСТОНСКОЙ ССР. ТОМ 21

ХИМИЯ * ГЕОЛОГИЯ. 1972, № 2

удК 662.749 .4

AHHE KАСБEPГ

\title{
НЕКОТОРЫЕ ДАННЫЕ О СОСТАВЕ НЕЙТРАЛЬНЫХ КИСЛОРОДНЫХ СОЕДИНЕНИЙ ЭСТОНСКОЙ СЛАНЦЕВОЙ смолы, Кипящих до $200^{\circ} \mathrm{C}$
}

Нейтральные кислородные соединения (НКС) являются самой большой и характерной группой соединений эстонской сланцевой смолы, но ввиду сложного состава и отсутствия достоверных методов анализа о них известно еще мало. Нами представлена общая характеристика НKC, кипящих до $3 \mathrm{CO} 0^{\circ}\left[{ }^{1}\right]$. Ниже приводятся некоторые данные об индивидуальном составе НКС, выкипающих до $200^{\circ}$. Названная часть НКС присутствует и в исходном сырье производства синтетических моющих веществ, обусловливая появление в технологической схеме дополнительных приемов и аппаратов $\left[^{2}\right]$. В связи с этим изучение состава НКС этой фракции смолы представляет интерес с точки зрения как улучшения качества синтетических моющих веществ, так и выяснения состава этой части НКС как нового специфичного сырья для химической промышленности.

Исходным веществом для исследования служила легкая смола туннельных печей плотностью $d_{20}^{20}$ 0,889. Проба смолы ректифицировалась на узкокипящие фракции на установке с разделительной способностью в 40 теоретических тарелок.

Кислородные соединения выделялись из фракций, кипящих в пределах температур $66-200^{\circ}$, адсорбционной хроматографией в колонке с окнсью алюминия. Во избежание возможного изменения НКС под действием щелочи предварительное обесфеноливание фракций не проводилось. Фенолы, попадающие во фракции НКС, не мешают анализу, так как в газохроматографнческой колонке, жидкой фазой которой является полярный полиэтиленгликоль, они задерживаются значительно сильнее, чем НКС соответствующих фракций.

Соотношение адсорбента и разделяемого вещества составляло $8: 1$, количество разделяемой фракции - 10 г. Элюентами служили петролейный эфир, диэтиловый эфир и ацетон. Последующий газохроматографический анализ показал, что петролейный эфир вымывал углеводороды, а кислородные соединения элюировались диэтиловым эфиром и ацетоном.

Фракция, выкипающая до $200^{\circ}$, составляет $24 \%$ от суммарной исходной смолы. Среднее содержание НКС этой части смолы, по данным адсорбционно-хроматографического разделения, равно $13 \%$.

Анализ фракций НКС был проведен на газовом хроматографе УХ-1. Для идентификации компонентов использовались времена выхода эталонных веществ - кетонов разного строения, а также реакционно-газохроматографические методы установления углеводородного скелета [3] и двойных связей $\left[{ }^{4}\right]$ кислородных соединений и определения кислородных соединений с прямой углеродной цепью [5]. 
Установление структуры углеродных скелетов кислородных соединений проводится гидрированием их в соответствующие углеводороды г доколоночном реакторе на активном платиновом катализаторе $(5 \%$ $\mathrm{P}$ i/силикагель ШСК) при температуре $330-350^{\circ}\left[{ }^{3}\right]$. Если тот же катализатор использовать в схеме с заколоночным реактором, а образовав шиеся углеводороды пропустить через молекулярные сита типа СаА, которые удерживают углеводороды с прямой цепью, можно установить кислородные соединения, имеющие прямую углеродную цепь [ $\left.{ }^{4}\right]$. Для определения двойных связей в кислородных соединениях их гидрируют на малоактивном платиновом катализаторе $(5 \% \mathrm{Pt} /$ хромосорб́ $W)$ в доколоночном реакторе при $300^{\circ}$. В этих условиях насыщаются двойные связи, а кислород от молекул не отщепляется [5].

Анализ, проведенный по описанной методике, показал, что НКС, выкипающие до $200^{\circ}$, содержат $66 \%$ соединений с прямой углеродной цепью. Для исследуемой области НКС суммарное содержание н-адканонов-2 отдельных фракций составляет $31 \%$. Ранее мы предполагали ['], что $\boldsymbol{H}$-алканоны-2 образуют примерно $35 \%$ от НКС, выкипающих до $300^{\circ}$. Можно все же считать, что их содержание несколько меньшее, так как результат $31 \%$ получен для низкокипящей области смолы, а содержание $\boldsymbol{H}$-алканонов-2 в НКС с повышением температуры кипения уменьшается.

\section{Содержание некоторых идентифицированных НКС в легкой смоле туннельных печей}

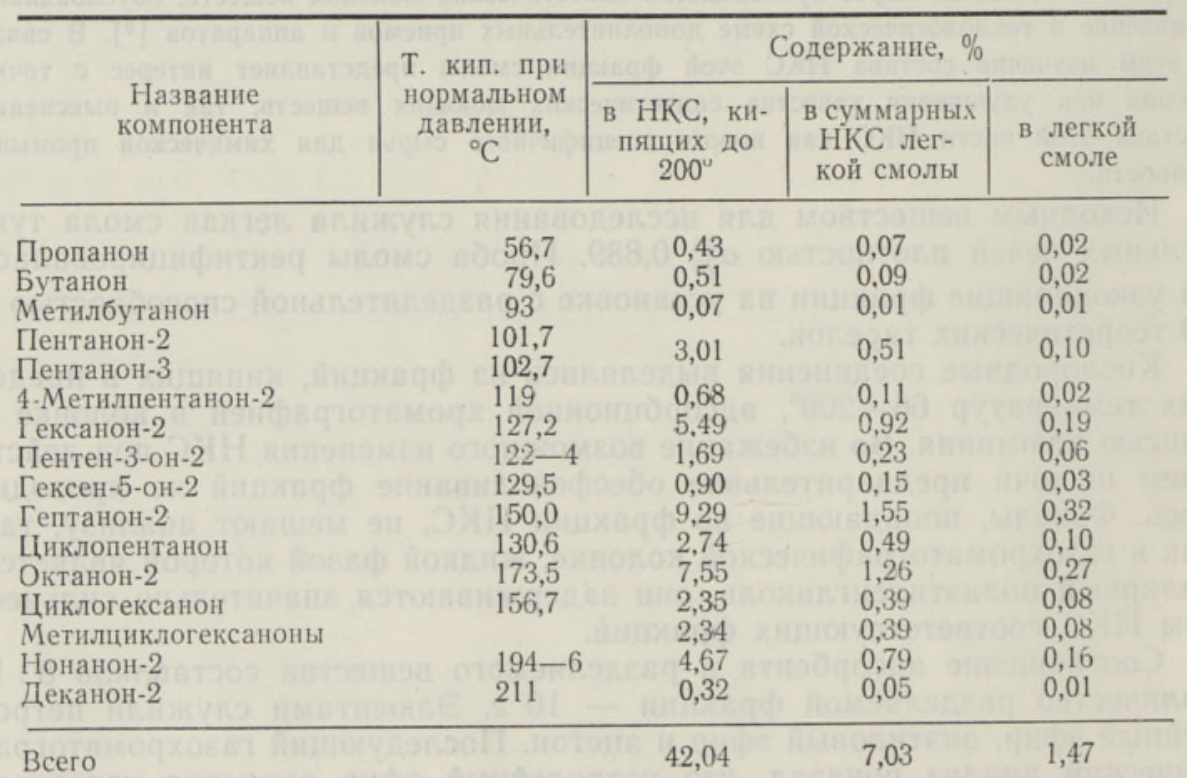

На рисунке изображена зависимость содержания кислородных соедикений с разной структурой в изученных НКС от температуры кипения. В области более низких температур кипения преобладают соединения с прямой углеродной цепью. При 125-130 возрастает содержание изо- и циклических соединений ввиду концентрирования в этой области циклопентанона. Увеличение содержания названных соединений в пределах температур $155-170^{\circ}$ обусловлено преобладанием циклогексанона и изомерных метилциклогексанонов.

Увеличение содержания ненасыщенных соединений с повышением температуры кипения не было неожиданным, так как вероятность присутст- 
вия двойной связи в молекуле возрастает с удлинением углеродной цепи. Интересно отметить высокую степень непредельности НҚС - 48\%. В области более высоких температур кипения она, вероятно, еще вьше. Как известно, содержание ненасыщенных соединений углеводородной части эстонской сланцевой смолы является также высоким [ $\left.{ }^{6}\right]$.

В исследуемых НКС идентифнцирован ряд соединений, которые приведены в таблице. Они составляют $42 \%$ от НКС, кипящих до $200^{\circ}$. Большинство из них - H-алканоны с карбонильной группой в положении 2. В области более низких температур кипения идентифицированы также некоторые разветвленные и ненасыщенные кетоны. Значительное количество из идентифицированных соединений составляют циклические кетоны: циклопентанон, циклогексанон, метилциклогексаноны. Большинство из неидентифицированных соединений носит ненасыщенный характер, значительную часть из них состав. ляют $\boldsymbol{H}$-алканоны-2 с двойной связью в

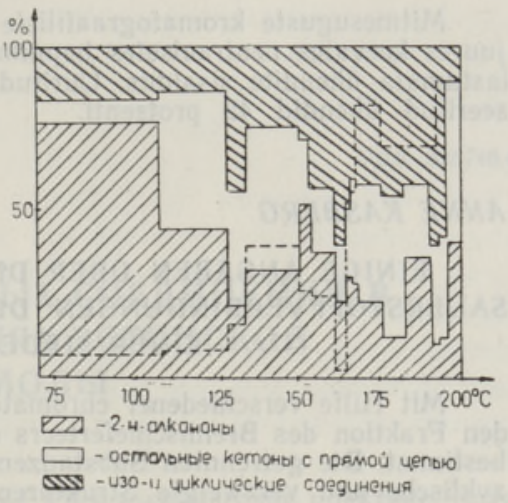

Зависимость содержания в нейтральных кислородных соединениях, кипящих до $200^{\circ} \mathrm{C}$, нормальных, изо-, циклических и непредельных соединений от температуры кипения. углеродной цепн.

Необходимость дальнейшего изучения состава НКС сланцевой смолы не вызывает сомнений. Возможности применения хроматографии и реакционной хроматографии в этом отношении далеко не исчерпаны, и сделанное до сих пор следует считать первыми шагами на этом пути.

\section{Выводы}

1. Из части легкой смолы туннельных печей, кипящей до $200^{\circ}$, выделены НКС и определено их содержание (13\%).

2. При изучении состава выделенных НКС выяснилось, что они содержат $66 \%$ соединений с прямой углеродной цепью, половину из которых составляют $н$-алканоны- $2 ; 48 \%$ исследованных кислородных соединений носит ненасыщенный характер.

3. Определено содержание соединений с прямой цепью, разветвленных и циклических, а также ченасыщенных в НКС эстонской сланцевой смолы в зависимости от температуры кипения.

4. Идентифицирован ряд кетонов с прямой углеродной цепью, разветвленных и циклических, составляющих $42 \%$ от НКС, кипящих до 200 ?

\section{Л ИТЕ Р А Т У Р А}

1. К асберг А., Клесмент И., Бюл. Горючие сланцы, № 1, 26 (1970).

2. Синтетические моющие вещества из сланцевой смолы (монография под редакцией С. И. Файнгольда), Таллин, 1964.

3. Клесмент И. Р., Р анг С. А., Э йзен О. Г., Нефтехимия, 3, № 6 (1963).

4. Краснощеков а Р., Клесмент И., Изв. АН ЭССР, Хим. Геол,, 18, № 1, 3 (1969).

5. Краснощекова Р., Клесмент И., Изв. АН ЭССР, Хим. Геол., 17, № 4, 346 (1968).

6 Эй зен О. Г., В сб.: Горючие сланцы, химия и технология, вып. 4, Таллин, 1961, c. 213 . 
ANNE KASBERG

\section{MONINGAID ANDMEID EESTI PÕLEVKIVIÕLI KUNI $200^{\circ} \mathrm{C}$ JUURES KEEVATE NEUTRAALSETE HAPNIKUUHENDITE KOOSTISEST}

Mitmesuguste kromatograafiliste meetodite abil määrati Eesti pōlevkiviōli kuni $200^{\circ}$ juures keevates neutraalsetes hapnikuühendites rea sirge ahelaga, iso-, tsükliliste ja kïlIastumata ühendite sisaldus. Uuritud piirkonna hapnikuühenditest moodustavad identifitseeritud ühendid 42 protsenti.

\section{ANNE KASBERG}

\section{EINIGE ANGABEN UBER DIE ZUSAMMENSETZUNG DER NEUTRALEN SAUERSTOFFVERBINDUNGEN DES ESTNISCHEN BRENNSCHIEFERTEERS VON EINER SIEDETEMPERATUR UNTER $200^{\circ} \mathrm{C}$}

Mit Hilfe verschiedener chromatographischer Methoden wurden in der niedrigsiedenden Fraktion des Brennschieferteers einige Sauerstoffverbindungen, hauptsächlich Ketone, bestimmt. Die getrennten Substanzen haben meistens eine gerade Kohlenwasserstoffkette; zyklische und verzweigte Strukturen sind in geringerem $\mathrm{MaBe}$ vorhanden. Der Gehalt an identifizierten, zum Teil ungesättigten Verbindungen beträgt $42 \%$ aller Sauerstoffverbindungen der untersuchten Fraktion. 